\title{
The electromagnetic radiation of extremely compressed coals
}

\author{
Roman Diakun ${ }^{1, *}$ \\ ${ }^{1}$ Institute of Geotechnical Mechanics named by N. Poljakov of National Academy of Sciences of \\ Ukraine, 49005, Dnipro, Simferopolska Str., 2a, Ukraine
}

\begin{abstract}
The article investigates the nature of changes in the level of radiation and absorption of electromagnetic oscillations by coal samples that are in an extremely stressful state. When performing the work, a stand of studying electromagnetic oscillations was assembled for different levels of compression stress of the rock. The results of changes in the amplitude of electromagnetic oscillations in the frequency range 0.5-1.5 and 66$110 \mathrm{MHz}$ for different values of compressive stresses of coal samples are given. It is shown that before the destruction of an extremely compressed coal sample, the level of electromagnetic oscillations decreases by a factor of 3 or more. This phenomenon can be used to predict sudden outbursts of coal and gas. It has been established that exposure to electromagnetic radiation of low energy intensity on the rock in the frequency range $0.5-$ 1.5 and $66-110 \mathrm{MHz}$ can be used as a tool for changing the stress-strain state of the rock in the modes of resonance of electromagnetic oscillations of the system "technogenic source of electromagnetic radiation extremely stressful rock".
\end{abstract}

\section{Introduction}

Currently, the problem of a reliable forecast of sudden coal and gas emissions remains unsolved. For example, it is known that the destruction of rocks is accompanied by the manifestation of electromagnetic radiation, in particular, the so-called piezoelectric effect. This is manifested during the implementation of the elastic potential energy of compression of the array in the form of dynamic destruction during unloading in the near-bottom part of the rock mass. To register it, it is enough to have a passive electromagnetic radiation sensor with an operating frequency of up to $40 \mathrm{kHz}$. But in order to determine the stress state, or the level of stored elastic energy before the destruction of the rock in advance, it is necessary to study the changes in the amplitude of electromagnetic radiation at higher frequencies.

High frequencies allow detecting violations in the rock structure at the micro level (less than $10^{-3} \mathrm{~cm}$ ), when the rock disturbances associated with the accumulation of energy in the bottom-hole part of the mine workings, or the accumulated energy of the rock mass in the zones of tectonic disturbances occur. Therefore, in this article, the dynamic destruction of coal was modeled like the phenomenon of a sudden ejection of coal and gas, only without

\footnotetext{
*Corresponding author: romen@ua.fm
} 
gas saturation.

Simulation of the limite stress condition of coal was performed by the method of compression along one axis of the sample in the form of a plate $[1,2]$ with the ratio of height to width as $1: 8$.

From the practice of observations, such as earthquakes [3], it is known that before active seismic processes, the phenomenon of "silence" occurs at frequencies of electromagnetic radiation of more than $1 \mathrm{MHz}$.

The idea of the work was to study at higher frequencies of the amplitude of electromagnetic oscillations in coal samples, with their ultimate compression, for example, in the frequency range $0.5-1.5$ and $66-110 \mathrm{MHz}$.

\section{Methods}

For these studies use the stand presented in Figure 1, where the active sensor 2 transmits electromagnetic oscillations in the frequency range $0.5-1.5$ and $66-110 \mathrm{MHz}$. In this case, the sensor 2 is also a premnik of electromagnetic oscillations, in case the rock from the receiver of electromagnetic oscillations becomes their source.

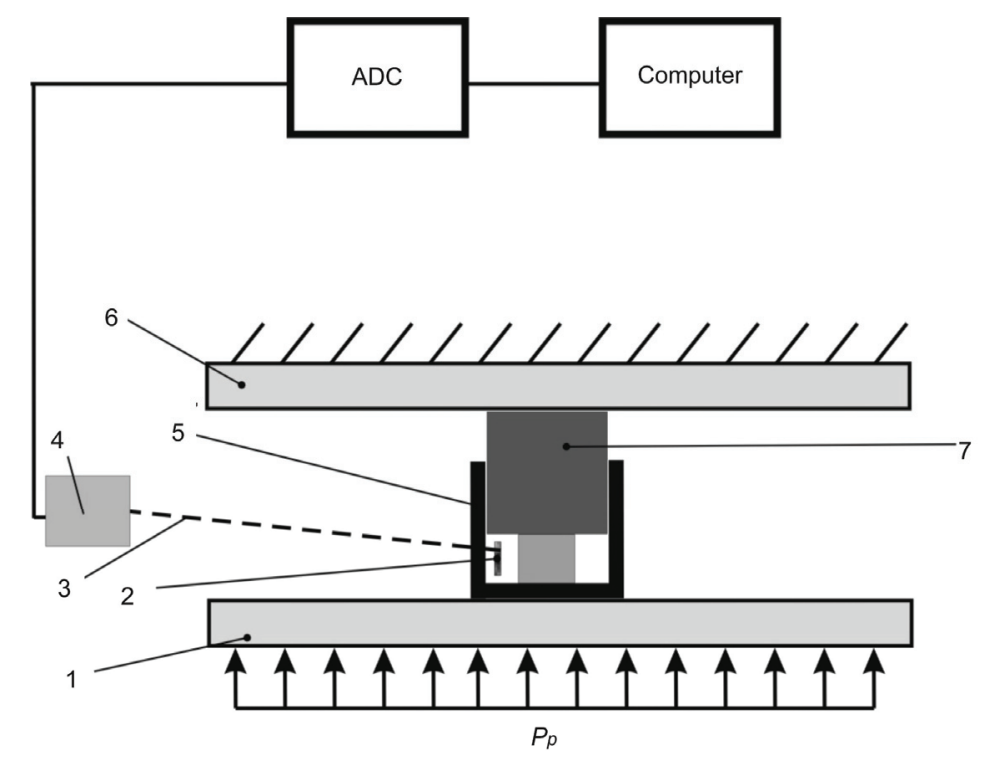

Fig. 1. The are schematic diagram of a test bench to study changes in electro-magnetic radiation and the absorption of high-frequency waves by rocks when they are loaded: 1 - lower press plate; 2 electromagnetic receiver-emitter; 3 - electromagnetic conductor; 4 - an emitter-receiver of electromagnetic waves; 5 - shielding housing test chamber; 6 - upper press plate; 7 - rod; ADC analog-to-digital converter; Computer - electronic computing machine; $P_{P}$ - press compression force.

For research, before the loading of the rock, the background of the electromagnetic component of the sensor 2 is measured on the stand shown in Figure 1.

In Figure 2, number 1 shows an example of the change in the amplitude of the background from the frequency of electromagnetic radiation.

Further, when the coal sample is loaded to a certain level of compression stresses, the background of electromagnetic radiation is measured, which is represented by number 2 in Figure 2. After this, further loading is carried out up to destruction, which is presented in Figure 2 by number 3 .

The analysis of the obtained data is performed, which indicate the moment when the 
rock is already close to the manifestation of dynamic destruction due to the accumulated potential energy of elastic compression.

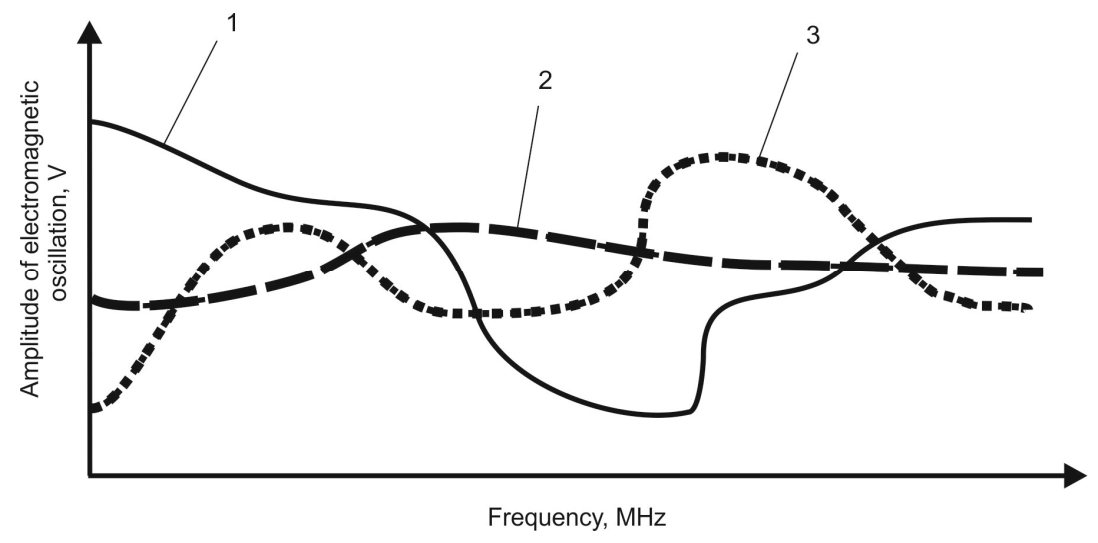

Fig. 2. The change in the amplitude of the electromagnetic oscillations in the frequency range 0.5$110 \mathrm{MHz}: 1$ - the background value of the electromagnetic oscillations before the tests, 2,3 - the value of the electromagnetic oscillations during the tests.

This method is interesting because it can predict the manifestation of the dangerous condition of the rock directly before destruction.

\section{Results and discussion}

As a result of the experiments performed, data on changes in the amplitude of electromagnetic radiation were obtained.

Using the example of the actual measurement of the amplitude of electromagnetic radiation for different compressive stresses of a coal plate (Fig. 3), the spectrum for the compressive stress of a coal sample of $37 \mathrm{MPa}$ is taken as the background value of the amplitude of electromagnetic radiation.

In the frequency range 93-110 MHz, with increasing compression stresses, the amplitude of the electromagnetic radiation is always less than the background value. For mechanical compressive stress 73 and $148 \mathrm{MPa}$ in the frequency range 66-75 and 87$93 \mathrm{MHz}$, the amplitude of the electromagnetic radiation increases relative to the background value. With a mechanical compressive stress of $110 \mathrm{MPa}$, the character of the change in the amplitude of electromagnetic radiation is similar to the background value, but, as a rule, $40-50 \%$ less.

The main feature is that at compression stresses of $186 \mathrm{MPa}$ and more, to the limit of strength, the level of amplitude of electromagnetic radiation before destruction is generally less than the initial (background) value by $85 \%$.

An example of the change in the amplitude of electromagnetic oscillations in the frequency range $0.5-1.5 \mathrm{MHz}$ is presented in Figure 4. For frequencies of $0.55-0.75 \mathrm{MHz}$ (Fig. 4), an increase in the amplitude of electromagnetic radiation up to $100 \%$ is observed at $73,110,148 \mathrm{MPa}$ compression of a coal sample relative to the background value (37 MPa) of the radiation amplitude in this range.

With an increase in the mechanical compression stress of coal, the amplitude increases relative to the background one by $50 \%$ or more in the frequency range $1.05-1.35,1.20-1.50$ and $0.9-1.5 \mathrm{MHz}$ for compression pressures of 73, 110 and $148 \mathrm{MPa}$, respectively. It can be seen that with an increase in mechanical compression stress to 73 and $110 \mathrm{MPa}$, the interval of increased amplitude of electromagnetic radiation shifts to the right along the $\mathrm{x}$-axis with geometric centers of 1.2 and $1.35 \mathrm{MHz}$, respectively. 


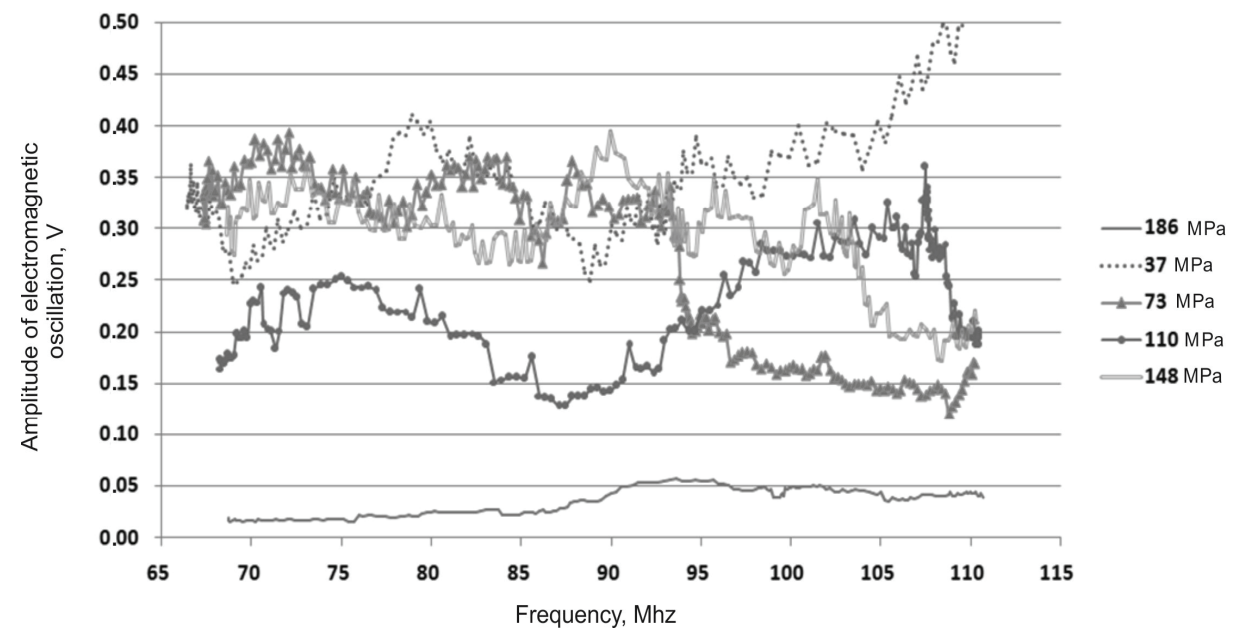

Fig. 3. The change in the amplitude of the electromagnetic oscillations in the frequency range 66$110 \mathrm{MHz}$.

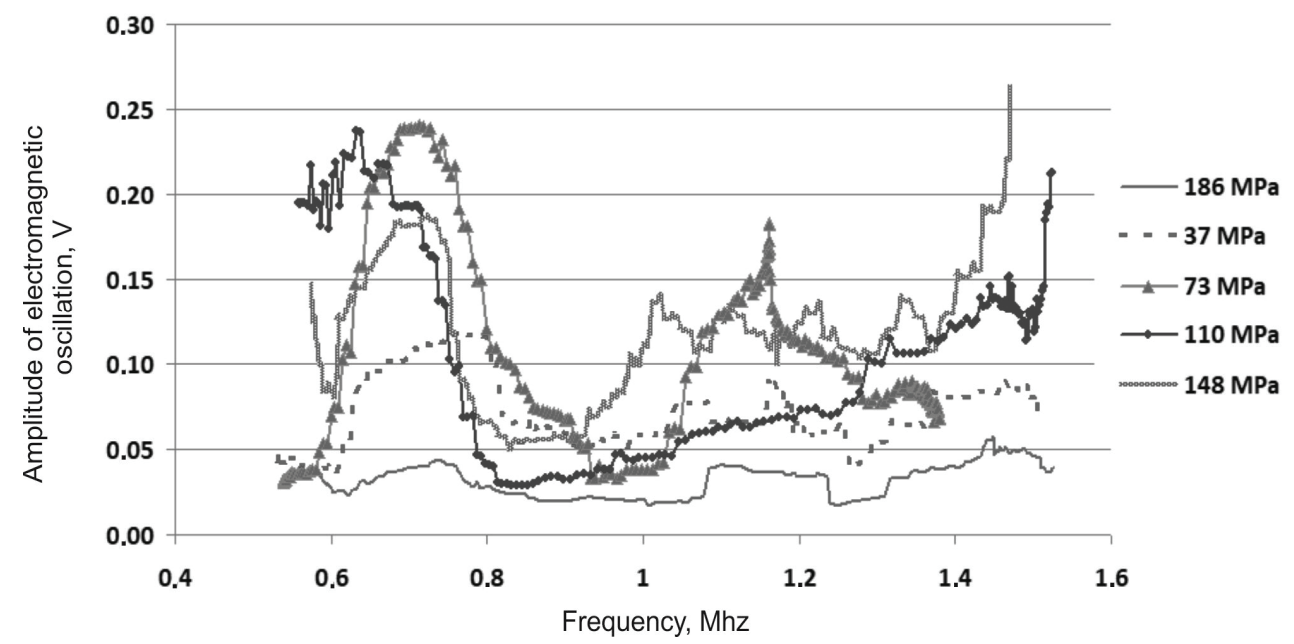

Fig. 4. Variation of the amplitude of electromagnetic oscillations in the frequency range $0.5-1.5 \mathrm{MHz}$.

With an increase in the mechanical compression stress of coal from 110 to $148 \mathrm{MPa}$, intervals of increased amplitude of electromagnetic radiation are combined, which were manifested earlier for 73 and $110 \mathrm{MPa}$ with the addition of an interval of $0.9-1.2 \mathrm{MHz}$ of increased amplitude of electromagnetic radiation.

And as a result, with a mechanical compression voltage of $186 \mathrm{MPa}$ or more, the amplitude of electromagnetic radiation decreases sharply by 75 and $55 \%$ when compared with the amplitude of electromagnetic radiation for compression stresses of 148 and $37 \mathrm{MPa}$, where $37 \mathrm{MPa}$ is the background, initial measurement level.

Before the dynamic destruction of extremely compressed coal $d_{4}$, there is a "silence" effect in the frequency range $0.5-1.5$ and $66-110 \mathrm{MPa}$.

\section{Conclusions}

It has been established for coal $d_{4}$ taken at the Pokrovska mine, which is in an extremely 
stressful condition when, in the frequency range $0.5-1.5$ and $66-110 \mathrm{MHz}$, the amplitude of electromagnetic radiation decreases by $80 \%$ or more (that is, silence is set ) from its initial background value - is a sign of reaching the tensile strength of the sample of coal. At the same time, at destruction up to $100 \%$ of the potential energy of compression of a coal sample can be realized before destruction.

Conversely, when the amplitude of electromagnetic radiation in the intervals of $0.5-1.5$ and $66-110 \mathrm{MHz}$ does not decrease below $60 \%$ of the background value, the destruction of coal to the level of fine fractions does not occur even at a level of compression stress of $300 \mathrm{MPa}$.

When the amplitude of electromagnetic radiation decreases by $60 \%$ or more in the frequency range $0.5-1.5 \mathrm{MHz}$, and in the range $66-110 \mathrm{MHz}$ does not decrease, then destruction to the level of fine fractions occurs at a load level of $150 \mathrm{MPa}$ with $50 \%$ of the potential energy coal compression before destruction.

A method for controlling the stress-strain condition of rocks based on the principle of recording the amplitude of the electromagnetic emission of rocks in the frequency ranges $0.5-1.5$ and $66-110 \mathrm{MHz}$ is proposed.

Before the dynamic destruction of the extremely compressed sample of the coal seam $d_{4}$, a "silence" effect occurs in the frequency range 0.5-1.5 and 66-110 MPa.

A stand has been developed for recording the amplitude of electromagnetic emission and its absorption by rocks under their mechanical load.

During the execution of electromagnetic effects of low energy intensity on rock samples during their mechanical loading to a level less than the tensile strength, the following was established. Rocks such as sandstone, coal and granite were not only sources of electromagnetic emissions, but also absorbed electromagnetic radiation. And after performing cyclic uniaxial mechanical loads of these rocks, it was found that their length in the direction of the action of the compression load did not decrease, but vice versa increased.

It was concluded that such effects of electromagnetic energy of low energy intensity on the rock can be used as a tool for changing in its stress-strain state in the modes of resonance of the electromagnetic oscillation of the system "man-made source of electromagnetic radiation - extremely intense rock".

\section{References}

1. Kijashko, U.I., Diakun, R.A. (2008). Mekhanizm radialno-posloynogo razrusheniya uglya v predelno napryazhennom sostoyanii pri razgruzke. Deformation and destruction of materials with defects and dynamic phenomena in rocks and workings: materials of the XVIII International Scientific School, Tavrichesky National University - Simferopol, 85-87.

2. Diakun, R.A., Podoliak, K.K., Diakun, I.L., Svetlichy, V.N. (2008). Modelirovaniye dinamicheskogo razrusheniya predelno napryazhennogo uglya po radial'no-posloynomu mekhanizmu vblizi tektonicheskogo narusheniya. Deformation and destruction of materials with defects and dynamic phenomena in rocks and workings: materials of the XVIII International Scientific School, Tavrichesky National University - Simferopol, 8587

3. Afroimovich, E.L., Zherebtsov, G.A., Perevalov, N.P. (2012). Seysmoionosfernyye i seysmoelektromagnitnyye protsessy v Baykal'skoy riftovoy zone. Russian Academy of Sciences, Siberian Branch, Institute of Solar-Terrestrial Physics, Institute of the Earth's Crust, Institute of Physical Materials Science. Novosibirsk: Publisher SB RAS, (35) 